\title{
Energy requirement for maintenance of growing and adult male lesser mouse deer (Tragulus javanicus) in captivity.
}

\begin{abstract}
A study was conducted to determine the energy requirement for maintenance of eight lesser mouse deer, consisting of four growing males (6-8 months of age) with average body weight of $1.4 \pm 0.2 \mathrm{~kg}$ and four adult males (>2 years of age) with average body weight of $1.6 \pm 0.2$ $\mathrm{kg}$. The animals were from the colony reared at the Department of Animal Science, Universiti Putra Malaysia. The experiment was based on a $2 \times 4$ factorial arrangement in Latin-Square design. The animals were kept in single pens and fed with different levels of feed $(70 \%, 80 \%$, $90 \%$ and $100 \%$ of ad libitum intake). The feed was made up of $95 \%$ pellet and $5 \%$ 'kangkong' (Ipomoea aquatica) leaves. The energy requirement for maintenance was determined by using the regression equations between metabolisable energy intake and energy retention or body weight change. Energy retention was calculated as the difference between metabolisable energy intake and heat production. The results showed that the metabolisable energy requirements for maintenance when calculated based on energy retention were 420.1 and $422.9 \mathrm{~kJ} \mathrm{~kg}-0.75 \mathrm{~d}-1$ for growing and adult mouse deer, respectively, and when calculated based on weight change the values were 435.1 and $436.9 \mathrm{~kJ} \mathrm{~kg}-0.75 \mathrm{~d}-1$, respectively. The efficiency of utilization of metabolisable energy for maintenance $(\mathrm{km})$ for growing mouse deer was 0.58 and that for adult mouse deer was 0.54 .
\end{abstract}

Keyword: Lesser mouse deer; Tragulus javanicus; Energy requirement for maintenance. 